\title{
A ética animal em Peter Singer e Tom Regan em virtude da problemática dos direitos universalizáveis dos animais
}

\author{
The animal ethics in Peter Singer And Tom Regan in the sake of the \\ problematic of the universalizable rights of the animals
}

\author{
TARINÊ CORTINA POETA CASTILHO DA SILVA ${ }^{1}$ \\ KATIA SALOMÃO ${ }^{2}$ \\ ANTONELLA MARQUES NEVES 3
}

\begin{abstract}
Resumo: O artigo aborda a universalização dos direitos dos animais, em relação à teoria da dignidade animal, apresentada por Peter Singer, e a condição moral de existência, analisada por Tom Regan. Assim, em Singer, constrói-se uma ética dos deveres humanos em relação aos animais, vez que defende a existência digna dos animais que, para o douto autor, se assemelha à existência da dignidade do homem. Mas, Singer não é desleixado com sua teoria, de maneira que fomenta, com base em Kant, uma distinção entre animal como ser senciente e homem como ser consciente. Regan sustenta a condição do sofrimento animal em analogia ao sofrimento humano, criando uma teoria do 'status moral do sofrimento', como ponto de partida para sua ética animal, já que o animal, bem como o homem, tem os mesmos níveis de empatia, sofrimentos e dignidade moral. Tais enfoques sobre a ética animal são contrapostos ao longo deste artigo; considera-se a condição animal, defendida na Declaração Universal dos Direitos dos Animais, que serve como forma de analisar os níveis de influência teórica sobre a construção desses direitos, além de realizar apontamentos a respeito da recepção desses direitos em território brasileiro. Assim, ao final, de forma tímida, o Brasil tornou-se signatário de tais instrumentos jurídicos internacionais e serão, por meio disso, cotejados contrapontos e analogias à dignidade animal e sua notória condição de ser senciente.
\end{abstract}

Palavras-chave: Dignidade. Sencientes. Direito dos Animais.

Abstract: The article addresses the universalization of animal rights, in relation to the theory of animal dignity, presented by Peter Singer, and the moral condition of existence, analyzed by Tom Regan. In Singer, we have a construction of an ethics of human duties in relation to animals, since it defends the dignified aspect of animals' existence, which, for the learned author, is similar to the existence of human dignity. But, Singer is not sloppy with his theory, in a way that, based on Kant, fosters a distinction between animal as sentient being and man as conscious being. Regan supports the condition of animal suffering in analogy to human suffering, creating a theory of 'moral status of suffering', as a starting point for his animal ethics, since the animal, as well as man, has the same levels of empathy, suffering and moral dignity. Such approaches to animal ethics are contrasted throughout this article; the animal condition is considered, defended in the Universal Declaration of the Rights of Animals, which serves as a way to analyze the levels of theoretical influence on the construction of these rights, in addition to making notes regarding the reception of these rights in Brazilian territory. Thus, in the end, in a timid manner, Brazil became a signatory to such international legal instruments and, through this, counterpoints and analogies to animal dignity and its notorious condition of being sentient will be compared.

Keywords: Dignity. Sentient. Animal Rights.

\footnotetext{
${ }^{1}$ Centro Universitário de Cascavel - UNIVEL. E-mail: tari.tc86@gmail.com

${ }^{2}$ Doutoranda em Filosofia (Unioeste - PR): E-mail: salomao@univel.br

${ }^{3}$ Mestranda em educação pela Unioeste - Cascavel: antonellaneves@yahoo.com.br
} 


\section{Introdução}

O presente artigo analisa a condição animal, no que tange à sua dignidade de existência e seus direitos universalizáveis, em face da abordagem de Peter Singer e de Tom Regan. Em Singer, os direitos dos animais são observados por causa da necessidade da construção da dignidade, a qual se assemelha à dignidade humana. Não obstante, no pensamento de Tom Regan, defende-se o status da moral e do sofrimento dos animais em analogia à condição humana, já que o animal, assim como o homem, tem os mesmos níveis de empatia, sofrimentos e dignidade moral. Há, até mesmo, como um reflexo dessas análises teóricas a despeito da condição animal, o tratado das Organizações das Nações Unidas da (ONU), que versa sobre os direitos dos animais (Declaração Universal dos Direitos dos Animais), sendo que o Brasil é signatário; por meio disso, cotejam-se os contrapontos e analogias à dignidade animal e sua notória condição de ser senciente.

A Declaração Universal dos Direitos dos Animais (1978) foi fortemente influenciada pela discussão sobre a 'ética animal', sendo que, no decorrer de seus quatorze artigos, trata acerca da dignidade dos animais, expondo que os humanos têm o dever de preservá-los, garantindo-lhes umas vida digna. Também, é responsabilidade humana evitar crueldades, sejam quais forem (físicas ou psicológicas), oferecendo a eles o direito de liberdade e dignidade, a fim de abarcar, dessa forma, as referidas teorias.

Todavia, Singer e Regan destacam suas preocupações diante da latente desigualdade entre o animal racional e o homo sapiens, surgindo disso a inquietação de ambos, tangível à desigualdade animal, aos maus tratos e à crueldade. Além disso, há a ausência de tratamento digno e respeito às leis, já que, apesar de existentes, não são efetivas, pois, em analogia a Singer e Regan, reafirma-se a necessidade de colocar em pauta a discussão no que se refere à conexão entre dignidade animal e humana, bem como entre consciência do homem e senciência animal.

Para Regan (2004), o ser humano, no ápice de seu desenvolvimento tecnológico, parece ter deixado sua racionalidade de lado, quando suprime o habitat natural dos animais apenas para atender aos seus próprios interesses e, sem manifestar qualquer preocupação, impossibilita a compensação digna para aqueles que lhes são fonte de subsistência. Mediante tal irracionalidade, por um lado, o direito se constrói, negando ao animal uma derradeira compreensão ou até mesmo garantias para sua condição de seres dignos e sencientes. Mas, por outro lado, quando o direito abarca tais condições, passa a ser negligenciado, como é o caso da Declaração Universal dos Direitos dos Animais.

Singer, em seus estudos, apresenta vários pontos necessários para a efetivação da igualdade animal. A palavra-chave é inclusão, pois incluí-los na consideração 
moral é meio para superação do especismo, que tem por definição o preconceito com seres de outras espécies. $\mathrm{O}$ autor afirma ser possível, com base na aplicação do princípio da universalidade e da generalidade, pensar em superar o especismo, atribuindo ao animal a condição de ser digno, igual e livre em sua existência.

Por isso, diante da grande preocupação apresentada por Singer e Regan sobre os direitos dos animais e sua dignidade, sobressalta-se a necessidade de uma análise ética da Declaração dos Direitos dos Animais, em face às teorias desses autores. Dessa forma, há a busca por uma conclusão lógica e fundamentada sobre a proteção dos animais enquanto seres sencientes, o que se faz urgente, diante do cenário de degradação ética e negligência jurídica sobre tais aspectos protetivos.

\subsection{Estatuto da Moral e Sofrimento de acordo com Peter Singer}

Peter Singer (1978), ao contrário da maioria dos pensadores, é um dos precursores no estudo dos direitos dos animais, considerando-os como seres capazes de sentir (ser senciente), visto que essa capacidade não se restringe apenas ao homo sapiens sapiens. Nesse sentido observa o autor:

Muitos filósofos e outros autores, de uma forma ou de outra, estabeleceram o princípio da igual consideração de interesses como princípio moral básico; mas não foram muitos os que reconheceram que este princípio se aplica aos membros das outras espécies, tal como à nossa própria. Jeremy Bentham foi um dos poucos que tiveram consciência deste fato. (...) Bentham aponta a capacidade de sofrimento como característica vital que concede a um ser o direito a uma consideração igual. A capacidade de sofrer - ou, mais estritamente, de sofrer e/ou de se alegrar ou estar feliz - não é apenas mais uma característica como a capacidade da linguagem ou de compreensão da matemática avançada. (SINGER, 1975, p.23-24)

Diante do conceito acima, tem-se que todos os animais são sujeitos que exprimem sofrimento, sendo tal conclusão basicamente empírica, bastando observar as reações de animais que são submetidos ao sofrimento.

Na visão de Singer (1975), é importante diferenciar o direito das coisas (res) do direito aqui analisado, o que se faz com uma simples analogia, pois não se pode dizer se uma pedra quer ou não ser jogada em um rio, já que ela não tem a capacidade de exprimir sentimentos. Contudo, se um peixe for retirado da água, visivelmente, irá sofrer, contorcer-se, tentando voltar ao seu habitat natural, ou seja, está sofrendo com a situação a qual foi submetido.

Peter Singer (1975) defende a capacidade de todos os seres serem detentores de sentimentos e capazes de sofrer, inclusive, aqueles animais/seres não humanos. Sendo assim, o sofrimento animal deve ter sua devida importância, pois o sofrer de um cão, de um porco e de uma criança é igualmente doloroso; dessa forma, deveriam ter um status moral de igualdade, conforme afirma Peter Singer (1975). 
Destarte, Singer (1975, apud FELIPE, 2002) traz o conceito divergente ao critério aristotélico cartesiano, que estabelece que a igualdade entre homens se efetiva por meio do dote da razão e da linguagem. O autor apresenta a definição do princípio da sensibilidade como real parâmetro para embasar a igualdade, não só humana, mas sim, de todos os seres. Nesse ínterim, o princípio supracitado deve nortear as reflexões sobre todos os quesitos e questionamentos que interessam não só aos semelhantes, mas a todos os seres que não apresentam a habilidade da fala, porém, são iguais em sensibilidade, sendo capazes de sentir, portanto, passíveis de sofrimento.

De acordo com o estatuto da moral e do sofrimento de Singer, todos os seres que são iguais em sensibilidade devem receber um tratamento adequado, garantindo-lhes a vida digna, presente em Singer, uma vez que os animais, de acordo com a teoria apresentada, são capazes de sentir, exprimindo seu 'sofrer' com base em reações distintas da fala, devendo ser respeitados dentro de sua dignidade, justamente, por possuírem a capacidade de sofrimento, isto é, por sua condição senciente.

\subsection{A Teoria dos Animais Não Humanos de Tom Regan}

Para Tom Regan, os direitos dos animais não se encontram na esfera do direito positivo, mas sim, nos direitos morais, que extrapolam leis que regem o ordenamento jurídico brasileiro ou internacional. O filósofo aponta que o erro fundamental, quando se refere aos direitos animais, é o fato de serem tratados como meros recursos, deixando de lado seus interesses (dor e sofrimento).

Em função disso, o pensador atribui ao animal os direitos morais básicos, ou seja, uma forma de garantir-lhes uma vida digna. Para ele, todos os seres possuem capacidade de sofrer, por isso, devem ser valorados na mesma medida, visto que o sofrimento animal é tão ruim quanto o sofrimento humano (REGAN, 2001, apud CARDOZO, 2011).

Nesse sentido, Cardoso (2011) evidencia que alguns animais não humanos assemelham-se aos humanos normais, de forma moralmente relevante, usando como fundamento a teoria de Regan, em sua 'Filosofia dos Direitos dos Animais', nos seguintes moldes:

Eles trazem o mistério de uma presença unificada psicológica para o mundo. Como nós, eles possuem uma pluralidade de capacidades sensorial, cognitiva, conativa e volitiva. Eles enxergam e ouvem, acreditam e desejam, lembram e preveem, planejam e pretendem. Mais do que isso, o que acontece com eles, lhes importa. Prazer e dor físicos - isso eles compartilham conosco. Além de medo e contentamento, raiva e solidão, frustração e satisfação, astúcia e imprudência. Estes e uma série de outros estados psicológicos e disposições coletivamente ajudam a definir o estado mental e 
relativo bem-estar daqueles (na minha terminologia) sujeitos-deuma-vida que conhecemos melhor como guaxinins e coelhos, castores e bisões, esquilos e os chimpanzés, você e eu. (REGAN, 2004, p. 16).

De acordo com Regan (2001, apud OLIVEIRA, 2004), a filosofia que versa sobre os direitos dos animais pede que a lógica da vida seja respeitada, logo, todo e qualquer argumento que enfatize a individualidade humana, consequentemente, implica que todo animal tem o mesmo valor. Veja-se:

Quando uma injustiça é absoluta, a reação é absoluta. Não se lutou para se reformar a escravatura, mas sim para acabar com a escravatura, não se luta para reformar o trabalho infantil, ou a subjugação da mulher, mas sim para aboli-los completamente. Em todos estes casos, a abolição é a única resposta moral. Reformar injustiças é simplesmente prolongar a injustiça. (REGAN, 2004, p. o1).

O pensador não tem o intuito de equivaler os animais aos seres humanos, mas sim, de mostrar suas semelhanças. Além disso, os fundamentos para que se possa garantir o direito a todos os seres vivos, independentemente a qual classe animal pertençam, devem ser embasados apenas no direito de viver e existir em dignidade e justiça. Isto justifica-se no fato de que todos os seres são sencientes, mesmo que a consciência seja aspecto próprio do animal humano.

\subsection{Da diferenciação entre Ser Consciente e Ser Senciente}

A capacidade humana de raciocinar está diretamente ligada ao livre arbítrio, sendo seres autônomos, capazes de agir e escolher livremente. Singer (1975) resgatou Kant, uma vez que admite em seus estudos que o raciocínio não é a única capacidade dos seres humanos, sendo capazes de sofrer e sentir prazer, dor, alegria, etc. Contudo, apenas os seres humanos não são escravos de suas vontades, isto é, podem ir contra aquilo que sua vontade ou inclinação lhe impõe. O ser humano, nesse aspecto, distingue-se do animal, pois, além de instintos, são dotados de raciocínio lógico, além da capacidade de consciência da autonomia.

Nesse ínterim, Kant (apud SINGER, 1975) afirma que as ações humanas, ao contrário das ações dos animais, não são guiadas apenas pelo desejo de evitar dor e procurar prazer. O agir humano distingue-se da exteriorização dos instintos e impulsos sencientes dos animais, vez que a consciência humana é capacitada em ponderar os sentimentos e controlar os instintos, produzindo no homem a capacidade autônoma de agir, segundo o dever.

O homem, em seu dever (Sollen), é o único ser que se torna dotado de vontade autônoma, fato que o distancia do animal, evidenciando-o ser consciente e senciente ao mesmo tempo. Dessa forma, Singer (1975) reconhece que a 
humanidade é composta de seres sencientes, bem como conscientes (apud SANDEL, 2012).

Já os animais não humanos, são seres puramente sencientes, ou seja, são guiados pelos seus institutos, sendo escravos dos apetites e desejos (inclinações), vez que sempre estão em busca da sua satisfação em evitar a dor, em prol ao prazer, não se assemelhando ao ser humano nesse quesito: isto porque o humano, apesar de possuir todos esses desejos, poderá por livre escolha decidir se realiza ou não determinada ação para saciar sua vontade (SANDEL, 2012). Nesse sentido, Sandel complementa no seguinte sentido:

Eis, portanto, a relação entre liberdade como autonomia e a concepção de Kant sobre moral. Agir livremente não é escolher as melhores formas para atingir determinado fim; é escolher o fim em si - uma escolha que os seres humanos podem fazer e bolas de bilhar (e a maioria dos animais) não podem (SANDEL, 2012, p.142)

Superada a diferenciação de seres sencientes e conscientes, torna-se importante frisar que, apesar dos animais não terem racionalidade humana, são criaturas com sentimentos, a saber, a felicidade, a angústia, dor, prazer, tristeza, dentre outros. Nesse ponto, eles assemelham-se ao ser humano, merecendo respeito e não discriminação, muito menos abusos pelo fato de não terem consciência autônoma para decidir pelo dever (SANDEL, 2012).

Nesse sentido, após a análise das teorias de Siger e Regan, fica evidente a capacidade que os animais possuem de sofrer e sentir; logo, sendo dotados de tais capacidades, devem ser respeitados, assim como são atribuídas aos ser humano as garantias básicas de dignidade.

\subsection{Os Animais no Mundo Jurídico versus a Dignidade Animal}

A Declaração Universal dos Direitos dos Animais é um diploma legal internacional, criado e idealizado por defensores dos direitos dos animais, em 15 de Outubro de 1978, que criou parâmetros jurídicos para os membros da Organização das Nações Unidas sobre os direitos dos animais.

Na Declaração Universal dos Direitos dos Animais, os humanos possuem o dever de preservar os animais, garantindo-lhes uma vida digna, a fim de proteger da crueldade, seja qual for (físicas ou psicológicas), além de propiciar a eles o direito de liberdade e de existência, sempre que possível. Apesar da proteção, o animal não deixa de ser entendido como meio para existência humana: fato que não exclui seu próprio direito à existência. A declaração afirma claramente que a vida animal tem valor, independentemente de sua utilidade, como se observa em seu art. $1^{\circ}$ "Todos os animais nascem iguais diante da vida, e têm o mesmo direito à existência".

Nesse sentido, Cardoso (2011) afirma que os animais devem ser tratados com 
dignidade pelo fato terem uma vida, sendo titulares de direito. Para Singer (1975), os animais não se diferenciam dos humanos em relação à dignidade, por serem considerados seres sencientes e não mera rés. Diante disso, pode-se inferir os animais como seres detentores de direitos, sendo necessária a preservação da sua dignidade.

A Declaração Universal dos Direitos dos Animais possui caráter totalmente protetivo e uma das práticas vedadas é o abandono, expresso no art. $6^{\circ}$, b; leia-se: "O abandono de um animal é um ato cruel e degradante". Considera-se um dos notórios exemplos de abandono o que ocorre principalmente com aqueles animais que, durante uma existência inteira, foram usados como força de trabalho, os quais deveriam ser cuidados, não descartados e substituídos como um objeto sem mais valor (CARDOSO, 2011).

De acordo com Singer (1975), sempre o que fala mais alto é o valor monetário dos animais; quando os animais perdem suas capacidades para o trabalho (a crueldade instaura-se no descarte que tolhe mais uma vez a dignidade animal), seja pela idade ou por alguma moléstia, passam a representar despesas ou empecilho para seu tutor.

Pelo tratado, o uso animal para o trabalho não o torna ilegal, nem mesmo o seu abate para consumo, porém, é necessário esclarecer que o trabalho não pode ser degradante e expor o animal a práticas cruéis, que lhe causem dor e sofrimento. Para aqueles que são criados para consumo, deve-se observar a dignidade animal, não os expondo a qualquer prática que cause sofrimento desnecessário e/ou exagerado, como visto no art. $9^{\circ}$ da declaração: "No caso do animal ser criado para servir de alimentação, deve ser nutrido, alojado, transportado e abatido, sem que para ele tenha ansiedade ou dor".

A Declaração Universal dos Direitos dos Animais (1978) foi recepcionada pela Constituição Brasileira, sendo o Brasil nação signatária, como se vê no artigo 225, $\S 1^{\circ}$, VII, o qual versa sobre a proibição aos maus tratos e atos cruéis com os animais, sendo tal ação tratada como tipo penal (art. 64 do decreto de lei 3.688/41), nos seguintes moldes: "Tratar animal com crueldade ou submetê-lo a trabalho excessivo: Pena - prisão simples, de dez dias a um mês, ou multa, de cem a quinhentos mil réis".

Os maus tratos tanto de animais domésticos quanto dos animais para o consumo são vedados legalmente, apesar de sua pouca observância em termos práticos e legítimos no dia a dia; isso foi evidenciado neste artigo, ficando a informação a título de complementação.

Apesar de os animais serem meios para o fim humano, Singer (1975) e Regan (2004) consideram-nos na condição de seres sencientes e dignos em si mesmos, devendo ter preservado o direito à sua existência, livre de crueldades ou maus 
tratos. O direito à existência diz respeito a um ramo específico da ética, a 'ética da existência animal', mediante a qual o animal deverá viver sua vida de acordo com sua natureza e seus desígnios.

Nem todos os adeptos da ética animal colocam-se contra a finalidade em relação ao consumo, umas vez que são necessários à subsistência humana. Contudo, deve-se garantir a vida e a existência animal da forma mais orgânica e natural possível.

Assim como nas teorias analisadas anteriormente, a declaração garante aos animais, destinados para consumo, o direito à dignidade, ou seja, como nas palavras do artigo $9^{\circ}$ da declaração, a vida do animal deve seguir de uma maneira que não cause a eles ansiedade ou dor. Não obstante, a proteção da vida animal é tão latente na declaração que, mesmo o animal morto dever ser tratado com dignidade, conforme $\mathrm{o}$ art. $13^{\circ}$ "O animal morto deve ser tratado com respeito".

Nesse ponto, há claramente a recepção das teorias de Singer e Regan, uma vez que, mesmo de forma implícita, seguiu a essência das teorias dos autores, em que os animais são capazes de sentir (sencientes), ou seja, seus sentimentos devem ser levados em consideração na forma de sua criação.

Diante disso, a proteção ao direito de uma vida digna está fortemente assegurada no sistema jurídico internacional, estando, inclusive, adequada às teorias de Peter Singer e Tom Regan, expandindo o conceito de animais como seres sencientes. Contudo, existe somente uma proteção de norma regulamentadora geral, quando recepcionada pelo ordenamento jurídico brasileiro, que deixa de ser protetiva e passa a ser punitiva, por meio das leis existentes. Essa visão, mormente punitiva, não causa impacto e muito menos eficácia quanto à problemática dos direitos animais em território pátrio.

\section{Conclusão}

Como aludido no decorrer deste artigo, a premissa que rege todo o trabalho consolida-se nas teorias de Peter Singer e Tom Regan de que animais são detentores de sentimentos. Partindo disso, tem-se que é possível que os seres humanos entendam suas vontades, pois, apesar da não serem dotados de comunicação verbal, suas ações denotam sofrimento, dor, medo, o que por certo é fundamento para as teorias apresentadas.

Destarte, diante do exposto, é dever do ser humano garantir aos animais uma vida digna, na qual possam, nas palavras de Peter Singer (1975), ser animais em sua plenitude, a saber, que a vaca possa "vaquear" e o sapo "sapear", ou seja, fazer aquilo que a natureza destinou; dessa forma, não podem ser impedidos de viver, sendo confinados, pois precisam satisfazer seus desejos sencientes.

Nesse sentindo, após a análise da declaração dos direitos dos animais, foi 
possível observar que as teorias de Singer e Regan foram recepcionadas por esse documento, uma vez que trazem em seu bojo o direito dos animais à proteção e a uma vida digna. Ainda que destinados para o consumo, há que se reconhecer seu direito à existência digna, já que são seres dotados de senciência e não consciência.

Para Kant, a consciência é o que determina a condição do homem escolher entre a boa vontade autônoma ou uma condição heterônoma, o que seria o ponto de maior diferenciação do homem e do animal. Assim sendo, o animal sente dor, tristeza, afeto, mas não escolhe entre o impulso e a razão, ou seja, não está capacitado naturalmente para conter suas inclinações. Singer resgata essa análise kantiana, contudo, atribui ao homem como ser consciente a capacidade de uma escolha ética ao que se destina aos animais. Na ética animal de Singer e Regané, o homem é o destinatário da responsabilidade pelo cuidado razoável das condições de existência dos animais e da preservação dos seus direitos.

Contudo, a legislação brasileira foi impertinente às premissas da declaração e das teorias, uma vez que, assim como a maioria das leis nacionais, traz apenas punição a atos de desrespeito aos animais em forma de prisão ou multa, não enfatizando a proteção e meios para que se alcance maior cuidado a eles.

Logo, conclui-se que existe o direito a uma vida digna diretamente ligada à Declaração Universal dos Direitos dos Animais. Contudo, há de se pesar que a legislação brasileira não garante direitos, pelo contrário, pune a violação desses direitos garantidos pela declaração, ou seja, ao invés de ser norma de proteção, é norma de punição. Tal fato carrega grande importância, pois a declaração é apenas norma geral de meios de proteção, devendo a legislação interna ser norma de aplicação dessas proteções, não apenas meio de punição do direito já violado.

Por fim, tem-se que a declaração dos direitos dos animais e as teorias de Regan e Singer caminham lado a lado, visando sempre à proteção do direito antes que ocorra sua violação, uma vez que entendem a capacidade de sentir e sofrer dos animais, mesmo não possuindo capacidade de consciência, comunicação rebuscada ou até autonomia da vontade.

\section{Referências}

BRASIL. Constituição (1988). Constituição da República Federativa do Brasil. Brasília, DF: Senado Federal: Centro Gráfico, 1988. 292 p.

BRASIL (Estado). Lei no 14.037, de 20 de março de 2003. Código Estadual de Proteção Aos Animais. Curitiba, PR.

CARDOSO, Waleska Mendes. Considerações Sobre a Teoria Incidental dos Direitos dos Animais de Tom Regan. 2011. Monografia (Especialização) - Curso de Filosofia, PPGF da Universidade Federal de Santa Maria, Santa Maria, 2011. Disponível em: <https://repositorio.ufsm.br/handle/1/9125>. Acesso em 25 de outubro de 2018.

FELIPE, Sônia T. Da Igualdade. Peter Singer e a Defesa Ética dos Animais Contra o 
A ética animal em Peter Singer e Tom Regan em virtude da problemática dos direitos universalizáveis dos animais

Especismo. Santa Catarina: Philosophien, 2002. 22-48 pp.

OLIVEIRA, Gabriela Dias de. A Teoria dos Direitos Animais Humanos e Não-Humanos, de Tom Regan. Florianópolis: Ethic@, 2004. 283-299 p.

ONU. Declaração Universal dos Direitos dos Animais. Bruxelas: UNESCO, 27 jan. 1978.

REGAN, Tom. Jaulas Vazias: encarando o desafio dos direitos dos animais. São Paulo: Lugano, 2004.

SANDEL, Michael J. Justiça o que é fazer a coisa certa. 6. ed. Rio de Janeiro: Civilização Brasileira, 2012. 334 p.

SINGER, Peter. Animal liberation. São Paulo: Lugano, 1975.

Submissão: 10.10.2018 / Aceite: 20.12.2019 